\title{
Association between initial prescribed minute ventilation and post-resuscitation partial pressure of arterial carbon dioxide in patients with post-cardiac arrest syndrome
}

\author{
Brian W Roberts ${ }^{1 *}$, J Hope Kilgannon ${ }^{1}$, Michael E Chansky ${ }^{1}$ and Stephen Trzeciak ${ }^{1,2}$
}

\begin{abstract}
Background: Post-cardiac arrest hypocapnia/hypercapnia have been associated with poor neurological outcome. However, the impact of arterial carbon dioxide $\left(\mathrm{CO}_{2}\right)$ derangements during the immediate post-resuscitation period following cardiac arrest remains uncertain. We sought to test the correlation between prescribed minute ventilation and post-resuscitation partial pressure of $\mathrm{CO}_{2}\left(\mathrm{PaCO}_{2}\right)$, and to test the association between early $\mathrm{PaCO}_{2}$ and neurological outcome.
\end{abstract}

Methods: We retrospectively analyzed a prospectively compiled single-center cardiac arrest registry. We included adult (age $\geq 18$ years) patients who experienced a non-traumatic cardiac arrest and required mechanical ventilation. We analyzed initial post-resuscitation ventilator settings and initial arterial blood gas analysis (ABG) after initiation of post-resuscitation ventilator settings. We calculated prescribed minute ventilation:

\section{$\mathrm{MV}(\mathrm{mL} / \mathrm{kg} / \mathrm{min})=[[$ tidal volume $(\mathrm{TV}) /$ ideal body weight $(\mathrm{IBW})] \times$ respiratory rate $(\mathrm{RR})]$}

for each patient. We then used Pearson's correlation to test the correlations between prescribed $\mathrm{MV}$ and $\mathrm{PaCO}_{2}$. We also determined whether patients had normocapnia $\left(\mathrm{PaCO}_{2}\right.$ between 30 and $\left.50 \mathrm{mmHg}\right)$ on initial $\mathrm{ABG}$ and tested the association between normocapnia and good neurological function (Cerebral Performance Category 1 or 2) at hospital discharge using logistic regression analyses.

Results: Seventy-five patients were included. The majority of patients were in-hospital arrests (85\%). Pulseless electrical activity/asystole was the initial rhythm in $75 \%$ of patients. The median (IQR) TV, RR, and MV were 7 (7 to 8) $\mathrm{mL} / \mathrm{kg}$, 14 (14 to 16) breaths/minute, and 106 (91 to 125) mL/kg/min, respectively. Hypocapnia, normocapnia, and hypercapnia were found in $15 \%, 62 \%$, and $23 \%$ of patients, respectively. Good neurological function occurred in $32 \%$ of all patients, and $18 \%, 43 \%$, and $12 \%$ of patients with hypocapnia, normocapnia, and hypercapnia respectively. We found prescribed MV had only a weak correlation with initial $\mathrm{PaCO}_{2}, \mathrm{R}=-0.40(P<0.001)$. Normocapnia was associated with good neurological function, odds ratio 4.44 (95\% Cl 1.33 to 14.85).

(Continued on next page)

\footnotetext{
* Correspondence: roberts-brian-w@cooperhealth.edu

${ }^{1}$ The Department of Emergency Medicine, Cooper University Hospital, Cooper Medical School of Rowan University, One Cooper Plaza, K152, Camden, NJ 08103, USA

Full list of author information is available at the end of the article
} 
(Continued from previous page)

Conclusions: We found initial prescribed MV had only a weak correlation with subsequent PaCO $\mathrm{C}_{2}$ and that early Normocapnia was associated with good neurological outcome. These data provide rationale for future research to determine the impact of $\mathrm{PaCO}_{2}$ management during mechanical ventilation in post-cardiac arrest patients.

Keywords: Cardiac arrest; Heart arrest; Cardiopulmonary resuscitation; Resuscitation; Anoxic brain injury; Shock; Hypocapnia; Hypercapnia; Minute ventilation

\section{Background}

After successful resuscitation from cardiac arrest, even with therapeutic hypothermia treatment [1-3], most patients either die in the hospital or suffer permanent, crippling neurological disability due to anoxic brain injury [4]. Finding new approaches to attenuate brain injury after return of spontaneous circulation (ROSC) is a high priority for resuscitation science. Partial pressure of arterial carbon dioxide $\left(\mathrm{PaCO}_{2}\right)$ is a major regulator of cerebral blood flow. Hypocapnia and hypercapnia after ROSC have previously been demonstrated to be associated with poor outcomes in both adult and pediatric post-cardiac arrest patients $[5,6]$. In theory, hypocapnia could decrease cerebral blood flow, inducing or exacerbating cerebral ischemia [7-9], while hypercapnia could increase intracranial pressure and compound metabolic acidosis, which is common after ROSC [6,10-12]. Furthermore, among pediatric postcardiac arrest patients, early exposure to $\mathrm{PaCO}_{2}$ derangements (that is on initial post-ROSC arterial blood gas (ABG)) was associated with in-hospital mortality, while exposure at 24 hours after ROSC was not associated [5], suggesting time sensitivity. There are important differences in the physiological and cardiac arrest characteristics of pediatric patients compared to adult patients. It is therefore unclear if early $\mathrm{PaCO}_{2}$ has the same association with neurological outcome in adult cardiac arrest patients.

Current American Heart Association (AHA) guidelines suggest an initial post-ROSC tidal volume (TV) of 6 to $8 \mathrm{~mL} / \mathrm{kg}$ (based on ideal body weight (IBW)) followed by titration to a $\mathrm{PaCO}_{2}$ of 40 to $45 \mathrm{mmHg}$ in patients resuscitated from cardiac arrest [13]. These guidelines go on to state there are no data on specific ventilation strategies in post-cardiac arrest syndrome. The current recommended approach can result in a time delay in optimizing $\mathrm{PaCO}_{2}$ (that is time to initial ABG data being available and subsequent ventilation adjustments). Although this period is usually brief, it is likely the time period when the injured brain is most susceptible to further damage. There is currently a paucity of data on the relationship between prescribed minute ventilation and early $\mathrm{PaCO}_{2}$ in post-cardiac arrest patients requiring mechanical ventilation. Determining this relationship is the first step towards developing a ventilation strategy aimed at more consistently achieving an optimal $\mathrm{PaCO}_{2}$ on the initial ABG after ROSC. Such a ventilation strategy could decrease the time to $\mathrm{PaCO}_{2}$ optimization in a greater proportion of patients.

We hypothesized initial post-resuscitation prescribed MV would have a weak correlation with the subsequent $\mathrm{PaCO}_{2}$. We also hypothesized that early $\mathrm{PaCO}_{2}$ would be associated with neurological outcome. The primary objective of this study was to test the correlation between initial post-resuscitation prescribed minute ventilation and subsequent $\mathrm{PaCO}_{2}$. Our secondary objective was to test if early $\mathrm{PaCO}_{2}$ (that is on initial ABG analysis after initiation of post-ROSC ventilation settings) was associated with neurological outcome.

\section{Methods}

\section{Setting}

We retrospectively analyzed a prospectively compiled and maintained cardiac arrest registry over a one year period (July 2010 to July 2011) at a single academic medical center, Cooper University Hospital in Camden, NJ, USA. We collected data pertaining to the index cardiac arrest event, and outcomes consistent with the Utstein style for reporting cardiac arrest research, including all post-ROSC variables recommended for postresuscitation research $[14,15]$. In order to prospectively identify and capture data on consecutive post-cardiac arrest patients, we utilized a previously described 24-hour per day, 7 -day per week paging system $[6,16]$. The Institutional Review Board approved this study with a waiver of written informed consent.

\section{Participants}

We included both in- and out-of-hospital adult postcardiac arrest patients who were mechanically ventilated after ROSC. We included adult (age $\geq 18$ years) patients who experienced a non-traumatic cardiac arrest (defined as a documented absence of pulse and cardiopulmonary resuscitation (CPR) initiated) and required mechanical ventilation after ROSC. We excluded patients who died prior to an arterial blood gas analysis being obtained.

\section{Data collection}

We abstracted the following variables: demographics, comorbidities, initial prescribed ventilator settings (that is $\mathrm{TV}$, respiratory rate (RR), fraction of inspired oxygen, and positive end expiratory pressure) after ROSC, initial 
ABG analysis after initiation of post-ROSC ventilator settings, post-cardiac arrest interventions (for example, percutaneous coronary interventions and therapeutic hypothermia), and neurological status at hospital discharge (defined by the Cerebral Performance Category (CPC)). Arterial blood gas analysis was performed using the Siemens RAPIDLab 1265 (Erlangen, Germany) and $\mathrm{pH}$-stat $\mathrm{PaCO}_{2}$ values (that is we analyzed $\mathrm{PaCO}_{2}$ at the patient's actual temperature as opposed to warming the sample). We entered all data into a dedicated Access database (Microsoft Corporation, Redmond, WA, USA) and exported to StatPlus version 2009 (AnalystSoft Inc., Alexandria, VA, USA) for analysis.

\section{Outcome measures}

The primary outcome was initial $\mathrm{PaCO}_{2}$ after initiation of post-ROSC ventilator settings. Secondary outcome was good neurological function at hospital discharge, defined as a CPC 1 or 2 . The CPC is a validated five-point scale of neurological disability and historically the most commonly used outcome measure in post-cardiac arrest research (1: good cerebral performance, 2: moderate cerebral disability, 3: severe cerebral disability, 4: coma/ vegetative state, 5: death) [14,17-19]. Patients with a CPC of 1 or 2 had sufficient cerebral function at discharge to live independently.

\section{Data analysis}

We began the analysis with descriptive statistics. We displayed categorical data as counts and proportions. We described continuous data as median values and IQR or mean values and standard deviation, based on distribution of data. Since normal lung volumes are predicted based on sex and height [20,21], we calculated an IBW for each patient using the following formulae [22]:

Male patients : $50+0.91($ centimeters of height-152.4)

Female patients : $45.5+0.91$ (centimeters of height-152.4)

We then calculated the initial prescribed MV $(\mathrm{mL} / \mathrm{kg} / \mathrm{min})$ for each patient. MV was calculated as:

$$
\mathrm{MV}(\mathrm{mL} / \mathrm{kg} / \mathrm{min})=[(\mathrm{TV} / \mathrm{IBW}) \times \operatorname{prescribed} \mathrm{RR}]
$$

We used Pearson's linear correlation to test the correlation between prescribed MV and initial post-resuscitation $\mathrm{PaCO}_{2}$. We then used linear regression analysis to calculate $\mathrm{R}^{2}$, using prescribed $\mathrm{MV}$ as the independent variable and subsequent $\mathrm{PaCO}_{2}$ as the dependent variable.

For the purposes of additional analyses, we divided the cohort by initial $\mathrm{PaCO}_{2}$ after initiation of post-ROSC ventilator settings into hypocapnia, normocapnia, and hypercapnia (defined as $\mathrm{PaCO}_{2} \leq 30,31$ to 49 , and $\geq 50 \mathrm{mmHg}$, respectively, based on previously published cutoffs in studies of traumatic brain injury and post-cardiac arrest) $[5,6,23]$. We used univariable logistic regression to test the association between early normocapnia and good neurological function at hospital discharge. In order to ensure early normocapnia was independently associated with good neurological outcome, we performed sensitivity analyses adjusting for candidate variables known to be strong predictors of poor outcome in post-cardiac arrest patients. We selected the following candidate variables for the regression models: (1) initial cardiac rhythm (asystole or pulseless electrical activity (PEA) versus ventricular fibrillation/ventricular tachycardia (VF/VT)), (2) prolonged duration of cardiopulmonary resuscitation (CPR duration $>20$ minutes) [4,24-29], (3) post-resuscitation shock (defined as systolic blood pressure $<100 \mathrm{mmHg}$ or vasopressor support required to maintain systolic blood pressure $>100 \mathrm{mmHg}$ during the first 24 hours after ROSC) [6,30,31], (4) metabolic acidosis (defined as one or more recorded base deficit $\leq-6 \mathrm{mmol} / \mathrm{L}$ during the first 24 hours after ROSC) [6,32], (5) age (decile), (6) pre-arrest comorbidities (that is Charlson comorbidities index) [33], (7) pre-arrest pulmonary disease, and (8) initiation of therapeutic hypothermia.

We also performed an additional multivariable logistic regression analysis to test the association between a narrower early $\mathrm{PaCO}_{2}$ range (between 35 and $45 \mathrm{mmHg}$ ) and good neurological function at hospital discharge.

\section{Results}

One hundred and thirteen patients met all inclusion criteria. Thirty-eight patients died prior to ABG analysis being obtained. Of the 75 included patients, the majority of patients suffered in-hospital cardiac arrests with PEA/ asystole as the initial rhythm (49/75 (65\%)), and few patients were out-of-hospital cardiac arrest patients with pulseless VF/VT as the initial rhythm (4/75 (5\%)). Therapeutic hypothermia was performed on $100 \%(4 / 4)$ of patients with out-of-hospital, VF/VT cardiac arrest (indicated population (that is Class I recommendation)) [13], and in $44 \%(33 / 75)$ of all patients. Coronary angiography was performed in $12 / 75$ (16\%) of patients and of these patients 7/12 (58\%) underwent percutaneous coronary intervention. A greater proportion of patients had pre-arrest pulmonary disease among patients with hypercapnia compared to normocapnia, $47 \%$ versus $23 \%$ respectively. However, this difference was not found to be statistically significant $(P=0.07$ using the Chi square test). Table 1 displays baseline data for all subjects in the cohort, as well as for patients with hypocapnia, normocapnia, and hypercapnia.

The majority of patients were found to have postresuscitation shock (69/75 (92\%)), as well as a metabolic acidosis (49/75 (65\%)) during the post-cardiac arrest period. Of note, $\mathrm{pH}$ was found to be lower among 
Table 1 Baseline data for all subjects at the time of cardiac arrest

\begin{tabular}{|c|c|c|c|c|}
\hline & $\begin{array}{c}\text { All subjects } \\
n=75\end{array}$ & $\begin{array}{c}\text { Hypocapnia } \\
n=11\end{array}$ & $\begin{array}{l}\text { Normocapnia } \\
\qquad n=47\end{array}$ & $\begin{array}{c}\text { Hypercapnia } \\
n=17\end{array}$ \\
\hline Age (years (SD)) & $66(16)$ & $71(16)$ & $66(16)$ & $62(15)$ \\
\hline Female gender (n (\%)) & $33(44)$ & $7(64)$ & $18(38)$ & $8(47)$ \\
\hline \multicolumn{5}{|l|}{ Pre-existing comorbidities (n (\%)) } \\
\hline diabetes & $33(44)$ & $4(36)$ & $23(49)$ & $6(35)$ \\
\hline known coronary artery disease & $18(24)$ & $6(55)$ & $8(17)$ & $4(24)$ \\
\hline hypertension & $44(59)$ & $9(82)$ & $29(62)$ & $6(35)$ \\
\hline malignancy & $17(23)$ & $3(27)$ & $11(23)$ & $3(18)$ \\
\hline renal insufficiency & $16(21)$ & $4(36)$ & $10(21)$ & $2(12)$ \\
\hline pulmonary disease & $22(29)$ & $3(27)$ & $11(23)$ & $8(47)$ \\
\hline cerebral vascular disease & $2(3)$ & 0 & $2(4)$ & 0 \\
\hline congestive heart failure & $10(13)$ & $1(9)$ & $6(13)$ & $3(18)$ \\
\hline Charlson comorbidity score [33] (median (IQR)) & 2 (1 to 4$)$ & 3 (2 to 4$)$ & $2(1$ to 4$)$ & $2(1$ to 6$)$ \\
\hline \multicolumn{5}{|l|}{ Arrest location (n (\%)) } \\
\hline Out-of-hospital & $11(15)$ & 0 & $6(13)$ & $5(29)$ \\
\hline In-hospital & $64(85)$ & $11(100)$ & $41(87)$ & $12(71)$ \\
\hline \multicolumn{5}{|l|}{ Initial arrest rhythm (n (\%)) } \\
\hline PEA/asystole & $56(75)$ & $7(64)$ & $35(74)$ & $14(82)$ \\
\hline VFNT & $19(25)$ & $4(36)$ & $12(26)$ & $3(18)$ \\
\hline CPR duration $>20$ minutes $(n(\%))$ & $9(12)$ & 0 & $4(9)$ & $5(29)$ \\
\hline
\end{tabular}

CPR, cardiopulmonary resuscitation; PEA, pulseless electrical activity; VF, ventricular fibrillation; VT ventricular tachycardia.

patients with hypercapnia compared to normocapnia 7.04 (6.98 to 7.13) versus 7.29 (7.15 to 7.37) respectively, $(P=<0.0001$ using the Mann-Whitney $U$-test), while no difference was found in bicarbonate between patients with hypercapnia compared to normocapnia 18 (14 to 23) versus 19 (14 to 23$) \mathrm{mmol} / \mathrm{L}$ respectively, $(P=0.91$ using the Mann-Whitney $U$-test). A lower $\mathrm{pH}$ among patients with hypercapnia is expected secondary to respiratory acidosis. Table 2 displays post-cardiac arrest data for all subjects, as well as for patients with hypocapnia, normocapnia, and hypercapnia.

The majority of patients were prescribed pressure regulated volume control as the initial mode of ventilation $(71 / 75(95 \%))$. Three patients $(4 \%)$ were prescribed volume control and one patient (1\%) was prescribed synchronized intermittent mandatory ventilation. The median and IQR TV, RR, and MV were 7 (7 to 8) $\mathrm{mL} / \mathrm{kg}, 14$ (14 to 16 ) breaths/minute and 106 (91 to 125$) \mathrm{mL} / \mathrm{kg} / \mathrm{min}$,

Table 2 Post-cardiac arrest data for all subjects (displayed as median (IQR) unless otherwise noted)

\begin{tabular}{|c|c|c|c|c|}
\hline & $\begin{array}{l}\text { All subjects } \\
\qquad n=75\end{array}$ & $\begin{array}{l}\text { Hypocapnia } \\
n=11\end{array}$ & $\begin{array}{l}\text { Normocapnia } \\
\qquad n=47\end{array}$ & $\begin{array}{l}\text { Hypercapnia } \\
\qquad n=17\end{array}$ \\
\hline \multicolumn{5}{|l|}{ Initial prescribed ventilation Settings } \\
\hline $\mathrm{FiO}_{2}^{\ddagger}(\%)$ & $100(80$ to 100$)$ & 100 (70 to 100$)$ & $100(68$ to 100$)$ & 100 (100 to 100$)$ \\
\hline PEEP $\left(\mathrm{cmH}_{2} \mathrm{O}\right)$ & $5(5$ to 5$)$ & $5(5$ to 5$)$ & $5(5$ to 5$)$ & $5(5$ to 5$)$ \\
\hline Tidal Volume (mL/kg) & 7 (7 to 8$)$ & $8(7$ to 8$)$ & 7 (7 to 8$)$ & 7 (6 to 7$)$ \\
\hline Respiratory rate (breaths/minute) & $14(14$ to 16$)$ & 14 (14 to 21$)$ & $14(14$ to 16$)$ & $14(12$ to 14$)$ \\
\hline Post-resuscitation shock $k^{\mathrm{a}}$ (n (\%)) & $69(92)$ & $11(100)$ & $41(87)$ & $17(100)$ \\
\hline Metabolic acidosis ${ }^{\mathrm{b}}(\mathrm{n}(\%))$ & $49(65)$ & $9(82)$ & $27(57)$ & $13(76)$ \\
\hline \multirow[t]{2}{*}{$\mathrm{pH}$} & 7.24 & 7.27 & 7.29 & 7.04 \\
\hline & (7.07 to 7.33$)$ & (7.05 to 7.34$)$ & (7.15 to 7.37 ) & (6.98 to 7.13 ) \\
\hline Bicarbonate (mmol/L) & 18 (13 to 23$)$ & 12 (7 to 18$)$ & 19 (14 to 23$)$ & 18 (14 to 23$)$ \\
\hline
\end{tabular}

${ }^{\mathrm{a}}$ Defined as systolic blood pressure $<100 \mathrm{mmHg}$ or vasopressor support required to maintain systolic blood pressure $>100 \mathrm{mmHg}$ during the first 24 hours after return of spontaneous circulation; ${ }^{b}$ Defined as a base deficit $\leq-6 \mathrm{mmol} / \mathrm{L}$ during the first 24 hours after return of spontaneous circulation; ${ }^{{ }^{\prime}} \mathrm{FiO}{ }_{2}$, fraction of inspired oxygen; PEEP, peak end expiratory pressure. 
respectively. The median (IQR) time from initiation of mechanical ventilation to obtaining the initial arterial blood gas was 120 (37.5 to 180) minutes. Hypocapnia, normocapnia, and hypercapnia were found in $15 \%(11 / 75)$, $62 \%$ (47/75), and $23 \%$ (17/75) of patients, respectively.

Figure 1 displays the relationship between initial postROSC prescribed $\mathrm{MV}$ and subsequent $\mathrm{PaCO}_{2}$. Initial post-resuscitation prescribed $\mathrm{MV}$ was found to have only a weak correlation with initial subsequent $\mathrm{PaCO}_{2}$, $\mathrm{R}=-0.40(P<0.001)$. Using linear regression analysis we found $R^{2}=0.16$, suggesting initial post-resuscitation $M V$ is responsible for only $16 \%$ of the variability in subsequent $\mathrm{PaCO}_{2}$. Of note, prescribed $\mathrm{RR}$ alone was also found to have a weak correlation with initial subsequent $\mathrm{PaCO}_{2}, \mathrm{R}=-0.26(P=0.02)$.

Thirty-two percent of all patients had good neurological function at hospital discharge. Figure 2 displays good neurological function at hospital discharge among patients with hypocapnia, normocapnia, and hypercapnia. Normocapnia was found to be associated with good neurological outcome on univariable analysis, odds ratio 4.44 (95\%CI 1.33 to 14.85$)$. Normocapnia remained associated with good neurological outcome on multiple sensitivity analyses (Table 3). A narrower $\mathrm{PaCO}_{2}$ range (between 35 and $45 \mathrm{mmHg}$ ) was not found to be associated with good neurological outcome 1.89 (95\%CI 0.68 to 5.23$)$.

\section{Discussion}

In this study, we found initial prescribed MV had only a weak correlation with subsequent $\mathrm{PaCO}_{2}$. We also found normocapnia on the initial ABG after initiation of postROSC ventilator settings was associated with good neurological function at hospital discharge. We believe these findings suggest (1) rapid achievement of normocapnia during the initial post-ROSC period could potentially improve neurological outcome and (2) given the prescribed MV cannot be used to reliably predict the subsequent $\mathrm{PaCO}_{2}$, early and multiple $\mathrm{ABG}$ analyses may be required during the initial post-ROSC period in order to achieve normocapnia.

We sought to test the correlation between initial postROSC prescribed $\mathrm{MV}$ and subsequent $\mathrm{PaCO}_{2}$ because given the association between $\mathrm{PaCO}_{2}$ derangements and poor outcome in different forms of brain injury [23,34-37], including post-cardiac arrest syndrome [5,6,38], we believe rapid achievement of normocapnia after ROSC could potentially attenuate the ongoing brain injury which occurs during post-cardiac arrest syndrome. The initial step towards developing a ventilation strategy aimed at achieving normocapnia immediately after ROSC, was to determine the relationship between initial post-ROSC prescribed MV and subsequent $\mathrm{PaCO}_{2}$.

After cardiac arrest many patients require mechanical ventilation. During mechanical ventilation the prescribed MV can be used to alter the $\mathrm{PaCO}_{2}$, which in turn can affect cerebral blood flow [13]. The prescribed MV is the product of the TV and the RR, and manipulation of either the TV or the RR will alter the MV and affect the $\mathrm{PaCO}_{2}$. In addition to identifying a weak correlation between initial prescribed $\mathrm{MV}$ and initial $\mathrm{PaCO}_{2}$, we also found a weak correlation between prescribed RR and initial $\mathrm{PaCO}_{2}$. The 2010 AHA Guidelines for Cardiopulmonary Resuscitation and Emergency Cardiovascular Care recommend that an initial TV of 6 to $8 \mathrm{~mL} / \mathrm{kg}$ be prescribed after ROSC [13]. This recommendation was based on acute respiratory distress syndrome (ARDS) data, which found lower tidal volume was associated

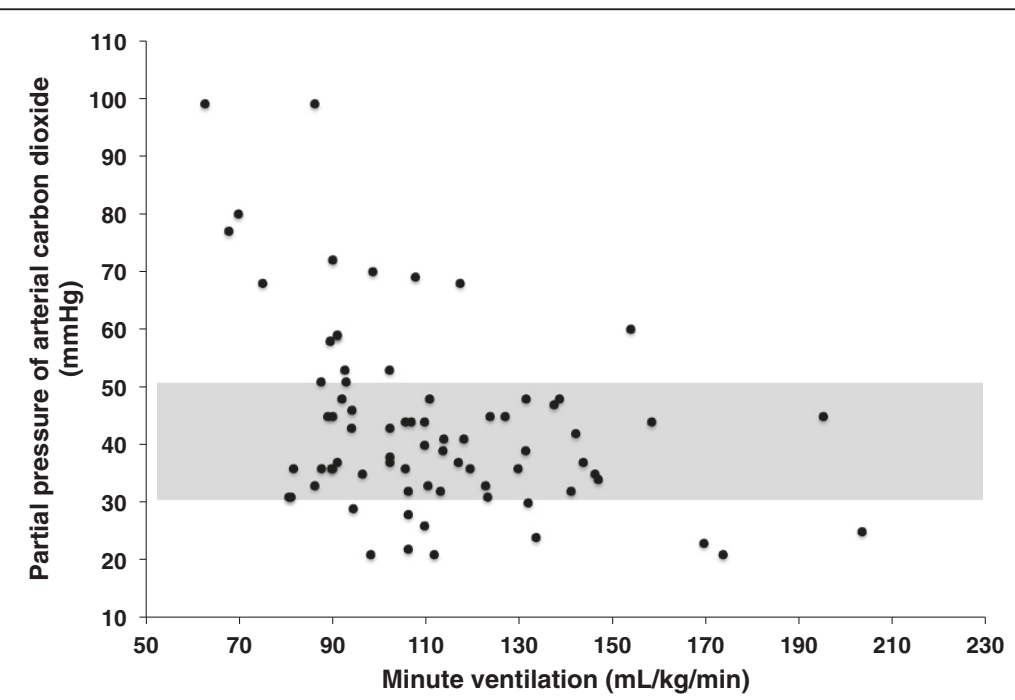

Figure 1 Relationship between initial post-resuscitation prescribed minute ventilation and partial pressure of arterial carbon dioxide on initial arterial blood gas analysis after initiation of post-resuscitation ventilation settings. Shaded area indicates range of normocapnia. 


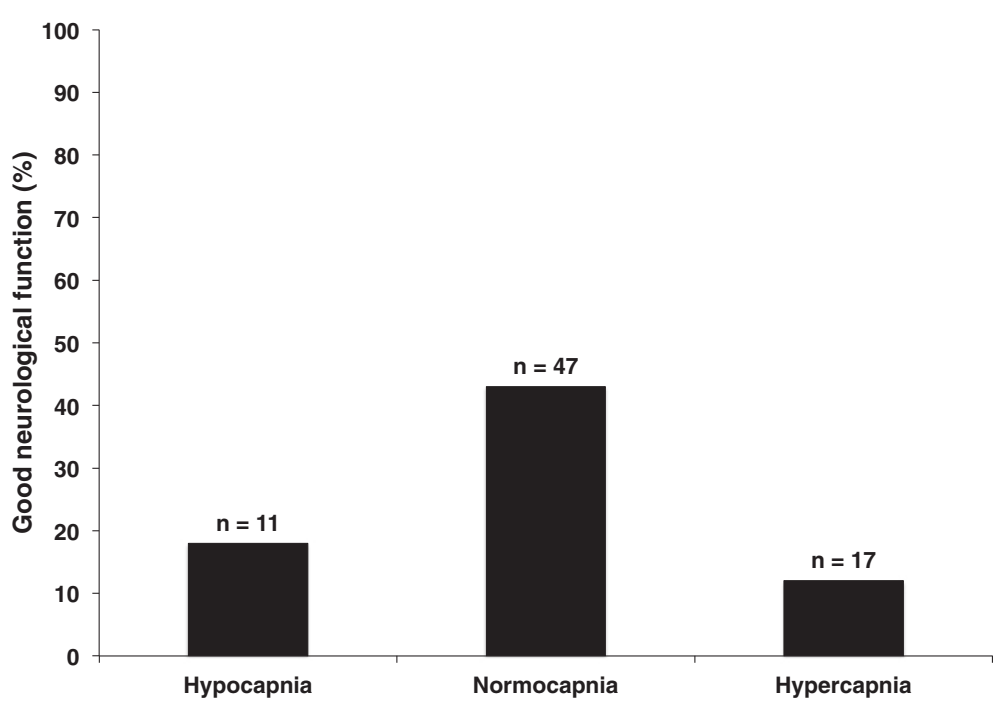

Figure 2 Proportion of patients with good neurological function at hospital discharge (defined as a Cerebral Performance Category (CPC) 1 or 2) in relation to hypocapnia $\left(\mathrm{PaCO}_{2} \leq 30 \mathrm{mmHg}\right)$, normocapnia $\left(\mathrm{PaCO}_{2} 31\right.$ to $\left.49 \mathrm{mmHg}\right)$, and hypercapnia $\left(\mathrm{PaCO}_{2} \geq 50\right.$ $\mathrm{mmHg}$ ) on initial arterial blood gas analysis after initiation of post-ROSC ventilation settings.

with a decrease in acute lung injury and improvement in clinical outcomes [22,39]. However, although lung injury has been demonstrated to occur in post-cardiac arrest syndrome the majority of patients die from neurological injury [16]. We suggest that a better post-cardiac arrest ventilation strategy would be a brain-centered approach aimed at preventing post-resuscitation $\mathrm{PaCO}_{2}$ derangements. Currently we are unaware of any data to support the use of a specific ventilation strategy in post-cardiac arrest syndrome. Specifically, there has been a paucity of data on the subject of initial prescribed $\mathrm{MV}$ and $\mathrm{PaCO}_{2}$ during the initial post-ROSC period. Although the AHA guidelines suggest titrating minute ventilation to achieve a $\mathrm{PaCO}_{2} 40$ to $45 \mathrm{mmHg}$, they go on to state there are no data on specific ventilation strategies in post-cardiac arrest syndrome. To our knowledge this is the first report describing the relationship between initial prescribed $\mathrm{MV}$ and $\mathrm{PaCO}_{2}$ in post-cardiac arrest syndrome.

$\mathrm{PaCO}_{2}$ is a major regulator of cerebral blood flow after brain injury. Although it has been suggested that the degree of reactivity to $\mathrm{PaCO}_{2}$ may be blunted during the initial post-cardiac arrest period [40-42], recent literature suggests it remains intact $[8,43,44]$. Hypercapnia has been demonstrated to decrease cerebrovascular resistance and increase blood flow, suggesting a potential benefit in patients suffering from ischemic brain injury $[8,45]$. A recent registry study of post-cardiac arrest patients found no difference in survival to hospital discharge between hypercapnic and normocapnic patients overall; however, among survivors they found hypercapnic patients to have a greater likelihood of being discharged directly to home as opposed to a rehabilitation facility or transferred to another hospital [38]. Contrary to these findings, recent studies of traumatic brain injury and post-cardiac arrest syndrome in both pediatric and adult patients have demonstrated hypercapnia to be association with poor clinical outcomes $[5,6,23]$. The association between hypercapnia and poor outcome has been suggested to be secondary to hypercapnia-induced cerebral vasodilation and increased intracranial volume resulting in increased intracranial pressure and decreased cerebral perfusion, as well as compounding metabolic acidosis, which is common after ROSC [6,10-12]. However, both traumatic brain injury and pediatric cardiac arrest patients have important differences in physiological characteristics compared to adult cardiac arrest patients. It therefore remains unclear if hypercapnia is associated with poor neurological outcome in adult cardiac arrest patients.

Post-resuscitation hypocapnia has also been demonstrated to be associated with poor outcome [5,6,38]. In contrast to hypercapnia, the association between hypocapnia and poor outcome has been suggested to be secondary to hypocapnia-induced cerebral vasoconstriction resulting in decreased cerebral blood flow and increased cerebral ischemia potentially exacerbating anoxic brain injury [6-9].

We sought to perform this study because we believe developing an initial ventilation strategy to prevent $\mathrm{PaCO}_{2}$ derangements immediately after resuscitation from cardiac arrest could potentially allow for a therapeutic approach to help attenuate brain injury associated with post-cardiac arrest syndrome. In this observational study we answered several preliminary questions: (1) initial prescribed MV had only a weak correlation with subsequent $\mathrm{PaCO}_{2}$, and (2) early normocapnia was associated with 
Table 3 Results of sensitivity analyses: multivariable logistic regression models of the association between Normocapnia (defined as partial pressure of arterial carbon dioxide 31 to $49 \mathrm{mmHg}$ ) on initial post-resuscitation arterial blood gas, and good neurological function (defined as Cerebral Performance Category 1 or 2 ) at hospital discharge

\begin{tabular}{|c|c|c|c|c|c|c|}
\hline Variable & Beta & Standard error & Odds Ratio & $95 \% \mathrm{LCl}$ & $95 \% \mathrm{UCl}$ & $P$-value \\
\hline Normocapnia & 1.51 & 0.62 & 4.54 & 1.34 & 15.35 & 0.01 \\
\hline PEA/asystole initial rhythm & -0.65 & 0.58 & 0.52 & 0.17 & 1.63 & 0.26 \\
\hline Variable & Beta & Standard Error & Odds Ratio & $95 \% \mathrm{LCl}$ & $95 \%$ UCl & $P$-value \\
\hline Normocapnia & 1.50 & 0.62 & 4.50 & 1.33 & 15.15 & 0.02 \\
\hline$C P R>20$ minutes & -0.34 & 0.89 & 0.71 & 0.13 & 4.06 & 0.70 \\
\hline Variable & Beta & Standard Error & Odds Ratio & $95 \% \mathrm{LCl}$ & $95 \%$ UCl & $P$-value \\
\hline Normocapnia & 1.24 & 0.63 & 3.46 & 1.01 & 11.89 & 0.04 \\
\hline Post-resuscitation shock ${ }^{a}$ & -2.16 & 1.14 & 0.11 & 0.01 & 1.08 & 0.05 \\
\hline Variable & Beta & Standard Error & Odds Ratio & $95 \% \mathrm{LCl}$ & $95 \%$ UCl & $P$-value \\
\hline Normocapnia & 1.36 & 0.63 & 3.89 & 1.14 & 13.26 & 0.03 \\
\hline Metabolic acidosis ${ }^{b}$ & -0.76 & 0.54 & 0.47 & 0.16 & 1.34 & 0.16 \\
\hline Variable & Beta & Standard Error & Odds Ratio & $95 \% \mathrm{LCl}$ & $95 \%$ UCl & $P$-value \\
\hline Normocapnia & 1.56 & 0.63 & 4.76 & 1.39 & 16.28 & 0.01 \\
\hline Age (decile) & -0.23 & 0.16 & 0.79 & 0.58 & 1.09 & 0.15 \\
\hline Variable & Beta & Standard Error & Odds Ratio & $95 \% \mathrm{LCl}$ & $95 \%$ UCl & $P$-value \\
\hline Normocapnia & 1.49 & 0.62 & 4.44 & 1.31 & 15.11 & 0.02 \\
\hline Charlson comorbidity index & -0.44 & 0.28 & 0.64 & 0.37 & 1.10 & 0.11 \\
\hline Variable & Beta & Standard Error & Odds Ratio & $95 \% \mathrm{LCl}$ & $95 \%$ UCl & $P$-value \\
\hline Normocapnia & 1.40 & 0.62 & 4.07 & 1.20 & 13.78 & 0.02 \\
\hline Pulmonary disease & -0.84 & 0.64 & 0.43 & 0.12 & 1.52 & 0.19 \\
\hline Variable & Beta & Standard Error & Odds Ratio & $95 \% \mathrm{LCl}$ & $95 \%$ UCl & $P$-value \\
\hline Normocapnia & 1.41 & 0.62 & 4.11 & 1.21 & 13.93 & 0.02 \\
\hline Therapeutic hypothermia & -0.44 & 0.54 & 0.64 & 0.22 & 1.86 & 0.42 \\
\hline
\end{tabular}

${ }^{a}$ Defined as systolic blood pressure $<100 \mathrm{mmHg}$ or vasopressor support required to maintain systolic blood pressure $>100 \mathrm{mmHg}$ during the first 24 hours after return of spontaneous circulation; ${ }^{b}$ Defined as a base deficit $\leq-6$ during the first 24 hours after return of spontaneous circulation; CPR, cardiopulmonary resuscitation; $\mathrm{LCl}$, lower confidence interval; $\mathrm{PEA}$, pulseless electrical activity; $\mathrm{UCl}$, upper confidence interval.

good neurological outcome. Our findings suggest that the initial post-resuscitation $\mathrm{PaCO}_{2}$ is not solely the result of the prescribed MV, and thus it is likely influenced by other treatment-related factors (for example, use of neuromuscular blocking agents, duration and technique of bag ventilation by hand prior to initiation of mechanical ventilation) and multiple patient-related factors (for example, etiology of cardiac arrest, lung compliance, lung injury, intrinsic respiratory drive, persistent post-resuscitation circulatory shock, dead space, body habitus). These data provide scientific rationale for further research to determine the other factors associated with $\mathrm{PaCO}_{2}$ derangements during the initial post-ROSC period. Determining such factors will allow for the development of a volume-targeted ventilation strategy, which focuses on initial prescribed MV adjusted for individual patient-related factors. Such a ventilator strategy could potentially achieve normocapnia more consistently on the initial ABG after ROSC, decreasing the need for ventilator adjustments and additional ABG analyses, and ultimately decrease the time to achievement of normocapnia.

We acknowledge that this study has important limitations to consider. First, we found prescribed MV to have only a weak correlation with initial post-resuscitation $\mathrm{PaCO}_{2}$, suggesting $\mathrm{PaCO}_{2}$ is also influenced by patientrelated factors; however, although this was a registry study of prospectively collected $\mathrm{PaCO}_{2}$ analyses and ventilator settings, patient-related factors were not initially collected and thus we were unable to determine what other factors were associated with initial post-resuscitation $\mathrm{PaCO}_{2}$. Many potentially important other factors are not routinely recorded in the patient record (for example, duration and technique of bag ventilation by hand prior to initiation of mechanical ventilation, lung compliance, lung injury, intrinsic respiratory drive, persistent post-resuscitation circulatory shock, dead space) and thus rigorous prospective research is required to determine the other determinates of initial post-resuscitation $\mathrm{PaCO}_{2}$. Second, this was an observational study and there exists the potential of 
unmeasured confounders (for example post-resuscitation lactic acidosis). Third, this study was limited to one center and it is possible that a study of larger scope could have found different results. Fourth, we defined hypocapnia and hypercapnia as $\mathrm{PaCO}_{2} \leq 30 \mathrm{mmHg}$ and $\mathrm{PaCO}_{2} \geq 50$ $\mathrm{mmHg}$, respectively, based on $\mathrm{PaCO}_{2}$ levels from previously published studies [5,6,23]. We did not find a narrower $\mathrm{PaCO}_{2}$ range to be associated good neurological outcome suggesting severe $\mathrm{PaCO}_{2}$ derangements may be more detrimental to neurological outcome than smaller $\mathrm{PaCO}_{2}$ derangements; however, exact $\mathrm{PaCO}_{2}$ levels associated with good neurological outcome are unknown. Fifth, we did not perform any monitoring of physiological parameters related to $\mathrm{PaCO}_{2}$, such as transcranial Doppler monitoring. Sixth, it is important to consider that the majority of the patients in this study were in-hospital and PEA/asystole cardiac arrests, and these patients are known to have an exceptionally poor prognosis for survival. Lastly, this was an observational study and thus we can only report an association between normocapnia and good neurological outcome, rather than infer causation.

\section{Conclusions}

In this sample of adult patients resuscitated from cardiac arrest, we found initial post-resuscitation prescribed MV had only a weak correlation with subsequent $\mathrm{PaCO}_{2}$. We also found early normocapnia was associated with good neurological function at hospital discharge. These data provide rationale for future research to determine the impact of $\mathrm{PaCO}_{2}$ management during mechanical ventilation in post-cardiac arrest patients.

\begin{abstract}
Abbreviations
ABG: arterial blood gas; AHA: American Heart Association; ARDS: acute respiratory distress syndrome; CPC: Cerebral Performance Category; CPR: cardiopulmonary resuscitation; IBW: ideal body weight; MV: minute ventilation; $\mathrm{PaCO}_{2}$ : partial pressure of carbon dioxide; PEA: pulseless electrical activity; ROSC: return of spontaneous circulation; RR: respiratory rate; TV: tidal volume; VT: ventricular tachycardia; VF: ventricular fibrillation.
\end{abstract}

\section{Competing interests}

The authors declare that they have no competing interests.

\section{Authors' contributions}

All authors have made substantial contributions to this paper: BWR supervised all aspects of the study and takes responsibility for the paper as a whole. BWR, ST, JHK, and MEC conceived this study. BWR and JHK acquired and managed the data. BWR and ST analyzed the data and interpreted results. BWR drafted the manuscript and all authors contributed substantially to its revision. All authors approved the manuscript in its final form.

\section{Author details}

${ }^{1} T$ The Department of Emergency Medicine, Cooper University Hospital, Cooper Medical School of Rowan University, One Cooper Plaza, K152, Camden, NJ 08103, USA. ${ }^{2}$ The Department of Medicine, Division of Critical Care Medicine, Cooper University Hospital, Cooper Medical School of Rowan University, Camden, NJ, USA.

Received: 24 December 2013 Accepted: 25 February 2014 Published: 7 March 2014

\section{References}

1. Bernard SA, Gray TW, Buist MD, Jones BM, Silvester W, Gutteridge G, Smith $\mathrm{K}$ : Treatment of comatose survivors of out-of-hospital cardiac arrest with induced hypothermia. N Engl J Med 2002, 346:557-563.

2. Hypothermia after Cardiac Arrest (HACA) study group: Mild therapeutic hypothermia to improve the neurologic outcome after cardiac arrest. N Engl J Med 2002, 346:549-556.

3. Nielsen N1, Wetterslev J, Cronberg T, Erlinge D, Gasche Y, Hassager C, Horn J, Hovdenes J, Kjaergaard J, Kuiper M, Pellis T, Stammet P, Wanscher M, Wise MP, Åneman A, Al-Subaie N, Boesgaard S, Bro-Jeppesen J, Brunetti I, Bugge JF, Hingston CD, Juffermans NP, Koopmans M, Køber L, Langørgen J, Lilja G, Møller JE, Rundgren M, Rylander C, Smid O, et al: Targeted temperature management at 33 degrees $C$ versus 36 degrees $C$ after cardiac arrest. $N$ Engl J Med 2013, 369:2197-2206.

4. Nadkarni VM, Larkin GL, Peberdy MA, Carey SM, Kaye W, Mancini ME, Nichol G, Lane-Truitt T, Potts J, Ornato JP, Berg RA: First documented rhythm and clinical outcome from in-hospital cardiac arrest among children and adults. Jama 2006, 295:50-57.

5. Del Castillo J, Lopez-Herce J, Matamoros M, Canadas S, Rodriguez-Calvo A, Cechetti C, Rodriguez-Nunez A, Alvarez AC: Hyperoxia, hypocapnia and hypercapnia as outcome factors after cardiac arrest in children. Resuscitation 2012, 83:1456-1461.

6. Roberts BW, Kilgannon JH, Chansky ME, Mittal N, Wooden J, Trzeciak S: Association between post resuscitation partial pressure of arterial carbon dioxide and neurological outcome in patients with post-cardiac arrest syndrome. Circulation 2013, 127:2107-2113.

7. Ausina A, Baguena M, Nadal M, Manrique S, Ferrer A, Sahuquillo J, Garnacho A: Cerebral hemodynamic changes during sustained hypocapnia in severe head injury: can hyperventilation cause cerebral ischemia? Acta Neurochir Supp/ 1998, 71:1-4

8. Buunk G, van der Hoeven JG, Meinders AE: Cerebrovascular reactivity in comatose patients resuscitated from a cardiac arrest. Stroke 1997, 28:1569-1573.

9. Yundt KD, Diringer MN: The use of hyperventilation and its impact on cerebral ischemia in the treatment of traumatic brain injury. Crit Care Clin 1997, 13:163-184.

10. Brian JE Jr: Carbon dioxide and the cerebral circulation. Anesthesiology 1998, 88:1365-1386.

11. Falkenbach $P$, Kamarainen A, Makela A, Kurola J, Varpula T, Ala-Kokko T, Perttila J, Tenhunen J: Incidence of iatrogenic dyscarbia during mild therapeutic hypothermia after successful resuscitation from out-ofhospital cardiac arrest. Resuscitation 2009, 80:990-993.

12. Neumar RW, Nolan JP, Adrie C, Aibiki M, Berg RA, Böttiger BW, Callaway C, Clark RS, Geocadin RG, Jauch EC, Kern KB, Laurent I, Longstreth WT Jr, Merchant RM, Morley P, Morrison LJ, Nadkarni V, Peberdy MA, Rivers EP, Rodriguez-Nunez A, Sellke FW, Spaulding C, Sunde K, Vanden Hoek T: Postcardiac arrest syndrome: epidemiology, pathophysiology, treatment, and prognostication: a consensus statement from the International Liaison Committee on Resuscitation (American Heart Association, Australian and New Zealand Council on Resuscitation, European Resuscitation Council, Heart and Stroke Foundation of Canada, InterAmerican Heart Foundation, Resuscitation Council of Asia, and the Resuscitation Council of Southern Africa); the American Heart Association Emergency Cardiovascular Care Committee; the Council on Cardiovascular Surgery and Anesthesia; the Council on Cardiopulmonary, Perioperative, and Critical Care; the Council on Clinical Cardiology; and the Stroke Council. Circulation 2008, 118:2452-2483.

13. Peberdy MA, Callaway CW, Neumar RW, Geocadin RG, Zimmerman JL, Donnino M, Gabrielli A, Silvers SM, Zaritsky AL, Merchant R, Vanden Hoek TL, Kronick SL, American Heart Association: Part 9: post-cardiac arrest care, American Heart Association Guidelines for Cardiopulmonary Resuscitation and Emergency Cardiovascular Care. Circulation 2010, 2010(122):S768-S786.

14. Jacobs I, Nadkarni V, Bahr J, Berg RA, Billi JE, Bossaert L, Cassan P, Coovadia A, D'Este K, Finn J, Halperin H, Handley A, Herlitz J, Hickey R, Idris A, Kloeck W, Larkin GL, Mancini ME, Mason P, Mears G, Monsieurs K, Montgomery W, Morley P, Nichol G, Nolan J, Okada K, Perlman J, Shuster M, Steen PA, Sterz $F$, et al: Cardiac arrest and cardiopulmonary resuscitation outcome reports: update and simplification of the Utstein templates for resuscitation registries: a statement for healthcare professionals from a task force of the International Liaison Committee on Resuscitation (American Heart Association, European Resuscitation Council, Australian 
Resuscitation Council, New Zealand Resuscitation Council, Heart and Stroke Foundation of Canada, InterAmerican Heart Foundation, Resuscitation Councils of Southern Africa). Circulation 2004, 110:3385-3397.

15. Langhelle A, Nolan J, Herlitz J, Castren M, Wenzel V, Soreide E, Engdahl J, Steen PA: Recommended guidelines for reviewing, reporting, and conducting research on post-resuscitation care: the Utstein style. Resuscitation 2005, 66:271-283.

16. Roberts BW, Kilgannon JH, Chansky ME, Mittal N, Wooden J, Parrillo JE, Trzeciak S: Multiple organ dysfunction after return of spontaneous circulation in postcardiac arrest syndrome. Crit Care Med 2013 41:1492-1501.

17. Brain Resuscitation Clinical Trial II Study Group: A randomized clinical study of a calcium-entry blocker (lidoflazine) in the treatment of comatose survivors of cardiac arrest. N Engl J Med 1991, 324:1225-1231.

18. Jennett $B$, Bond $M$ : Assessment of outcome after severe brain damage. Lancet 1975, 1:480-484.

19. Trzeciak S, Jones AE, Kilgannon JH, Fuller BM, Roberts BW, Parrillo JE, Farrar $\mathrm{JT}$ : Outcome measures utilized in clinical trials of interventions for post-cardiac arrest syndrome: a systematic review. Resuscitation 2009, 80:617-623

20. Crapo RO, Morris AH, Clayton PD, Nixon CR: Lung volumes in healthy nonsmoking adults. Bull Eur Physiopathol Respir 1982, 18:419-425.

21. Crapo RO, Morris AH, Gardner RM: Reference spirometric values using techniques and equipment that meet ATS recommendations. Am Rev Respir Dis 1981, 123:659-664.

22. The Acute Respiratory Distress Syndrome Network: Ventilation with lower tidal volumes as compared with traditional tidal volumes for acute lung injury and the acute respiratory distress syndrome: the acute respiratory distress syndrome network. N Engl J Med 2000, 342:1301-1308.

23. Davis DP, Idris AH, Sise MJ, Kennedy F, Eastman AB, Velky T, Vilke GM, Hoyt $D B$ : Early ventilation and outcome in patients with moderate to severe traumatic brain injury. Crit Care Med 2006, 34:1202-1208.

24. Gaul GB, Gruska M, Titscher G, Blazek G, Havelec L, Marktl W, Muellner W, Kaff A: Prediction of survival after out-of-hospital cardiac arrest: results of a community-based study in Vienna. Resuscitation 1996, 32:169-176.

25. Hajbaghery MA, Mousavi G, Akbari H: Factors influencing survival after inhospital cardiopulmonary resuscitation. Resuscitation 2005, 66:317-321.

26. Langhelle A, Tyvold SS, Lexow K, Hapnes SA, Sunde K, Steen PA: In-hospital factors associated with improved outcome after out-of-hospital cardiac arrest: a comparison between four regions in Norway. Resuscitation 2003, 56:247-263.

27. Peberdy MA, Kaye W, Ornato JP, Larkin GL, Nadkarni V, Mancini ME, Berg RA Nichol G, Lane-Trultt T: Cardiopulmonary resuscitation of adults in the hospital: a report of 14,720 cardiac arrests from the National Registry of Cardiopulmonary Resuscitation. Resuscitation 2003, 58:297-308.

28. Tok D, Keles GT, Toprak V, Topcu I: Assessment of in-hospital cardiopulmonary resuscitation using Utstein template in a university hospital. Tohoku J Exp Med 2004, 202:265-273

29. Lee CC, Tsai MS, Fang CC, Chen YJ, Hui-Ming M, Huang CH, Chen WJ, Chen SC: Effects of pre-arrest comorbidities on 90-day survival of patients resuscitated from out-of-hospital cardiac arrest. Emerg Med J 2011, 28:432-436

30. Kilgannon JH, Roberts BW, Reihl LR, Chansky ME, Jones AE, Dellinger RP Parrillo JE, Trzeciak S: Early arterial hypotension is common in the post-cardiac arrest syndrome and associated with increased in-hospital mortality. Resuscitation 2008, 79:410-416.

31. Trzeciak S, Jones AE, Kilgannon JH, Milcarek B, Hunter K, Shapiro NI, Hollenberg SM, Dellinger P, Parrillo JE: Significance of arterial hypotension after resuscitation from cardiac arrest. Crit Care Med 2009, 37:2895-2903. quiz 2904.

32. Hodgman El, Morse BC, Dente CJ, Mina MJ, Shaz BH, Nicholas JM, Wyrzykowski AD, Salomone JP, Rozycki GS, Feliciano DV: Base deficit as a marker of survival after traumatic injury: consistent across changing patient populations and resuscitation paradigms. J Trauma Acute Care Surg 2012, 72:844-851.

33. Murray SB, Bates DW, Ngo L, Ufberg JW, Shapiro NI: Charlson Index is associated with one-year mortality in emergency department patients with suspected infection. Acad Emerg Med 2006, 13:530-536.

34. Muizelaar JP, Marmarou A, Ward JD, Kontos HA, Choi SC, Becker DP, Gruemer $\mathrm{H}$, Young HF: Adverse effects of prolonged hyperventilation in patients with severe head injury: a randomized clinical trial. J Neurosurg 1991, 75:731-739.

35. Greisen G, Munck H, Lou H: Severe hypocarbia in preterm infants and neurodevelopmental deficit. Acta Paediatr Scand 1987, 76:401-404.

36. Plum F: Hyperpnea, hyperventilation, and brain dysfunction. Ann Intern Med 1972, 76:328

37. Rout MW, Lane DJ, Wollner L: Prognosis in acute cerebrovascular accidents in relation to respiratory pattern and blood gas tensions. Br Med J 1971, 3:7-9.

38. Schneider AG, Eastwood GM, Bellomo R, Bailey M, Lipcsey M, Pilcher D, Young P, Stow P, Santamaria J, Stachowski E, Suzuki S, Woinarski NC, Pilcher $\mathrm{J}$ : Arterial carbon dioxide tension and outcome in patients admitted to the intensive care unit after cardiac arrest. Resuscitation 2013, 84:927-934.

39. Tremblay LN, Slutsky AS: Ventilator-induced lung injury: from the bench to the bedside. Intensive Care Med 2006, 32:24-33.

40. Krep H, Brinker G, Pillekamp F, Hossmann KA: Treatment with an endothelin type A receptor-antagonist after cardiac arrest and resuscitation improves cerebral hemodynamic and functional recovery in rats. Crit Care Med 2000, 28:2866-2872.

41. Krep H, Brinker G, Schwindt W, Hossmann KA: Endothelin type A-antagonist improves long-term neurological recovery after cardiac arrest in rats. Crit Care Med 2000, 28:2873-2880.

42. Nemoto EM, Snyder JV, Carroll RG, Morita H: Global ischemia in dogs: cerebrovascular CO2 reactivity and autoregulation. Stroke 1975, 6:425-431

43. Kagstrom E, Smith ML, Siesjo BK: Cerebral circulatory responses to hypercapnia and hypoxia in the recovery period following complete and incomplete cerebral ischemia in the rat. Acta Physiol Scand 1983, 118:281-291.

44. Safar P, Xiao F, Radovsky A, Tanigawa K, Ebmeyer U, Bircher N, Alexander $\mathrm{H}_{\text {, }}$ Stezoski SW: Improved cerebral resuscitation from cardiac arrest in dogs with mild hypothermia plus blood flow promotion. Stroke 1996, 27:105-113.

45. Vannucci RC, Towfighi J, Heitjan DF, Brucklacher RM: Carbon dioxide protects the perinatal brain from hypoxic-ischemic damage: an experimental study in the immature rat. Pediatrics 1995, 95:868-874.

doi:10.1186/2110-5820-4-9

Cite this article as: Roberts et al.: Association between initial prescribed minute ventilation and post-resuscitation partial pressure of arterial carbon dioxide in patients with post-cardiac arrest syndrome. Annals of Intensive Care 2014 4:9.

\section{Submit your manuscript to a SpringerOpen ${ }^{\circ}$ journal and benefit from:}

- Convenient online submission

- Rigorous peer review

- Immediate publication on acceptance

- Open access: articles freely available online

- High visibility within the field

- Retaining the copyright to your article

Submit your next manuscript at $>$ springeropen.com 